\title{
Correspondence
}

\section{Fatal anaphylactic reaction to oral diclofenac sodium}

To the Editor:

Diclofenac sodium is commonly used in pain clinic and peri-operatively. We report a fatal anaphylactic reaction to oral diclofenac in a nine-year-old girl hospitalised for "transient synovitis". She had no history of atopy or cardio-respiratory illness and her clinical investigations were unremarkable. After symptomatic improvement on oral nimsulide and limb traction, oral diclofenac $25 \mathrm{mg}$ twice daily was prescribed at discharge. At home, after a first dose of diclofenac, she complained of body aches, itching, showed cutaneous flushing and became febrile $\left(38.9^{\circ} \mathrm{C}\right)$. Attributing her symptoms to fever, a second dose was given within two hours. Soon, the girl became restless, developed a generalised body rash and choking sensation. Within $35 \mathrm{~min}$, she was brought to the ICU gasping, cyanosed, pulseless, with mid-dilated weakly reactive pupils and was intubated. Aggressive hemodynamic and respiratory support was provided but failed to resuscitate the child.

The second dose of diclofenac probably lead to a fulminant allergic reaction while delayed hospitalisation likely proved fatal. Should routine sensitivity tests be performed with diclofenac sodium? This drug is considered safe with a worldwide experience of 7.6 million patients per year. ${ }^{1} \mathrm{~V}$ an der Klauw et al. found 30 cases $^{2}$ of probable anaphylaxis to diclofenac in 992 reports on drug reaction. A fatal drug reaction following im diclofenac has been reported, ${ }^{3}$ but sodium metabisulphite preservative as a cause was not ruled out. In a singular report of reaction to oral diclofenac, the patient survived due to prompt resuscitation. ${ }^{4}$. It is therefore essential to remain aware of the toxic profile of all drugs. Prompt recognition and treatment of serious complications can help avert such untoward outcomes.

Indu Sen M D

Sukanya M itra M D

Kanti K. Gombar M D

Chandigarh, India

References

1 O'Brien WM. Adverse reactions to nonsteroidal antiinflammatory drugs. D iclofenac compared with other nonsteroidal anti-inflammatory drugs. Am J M ed 1986; 80: 70-80.

2 Van der Klauw M M, Wilson JH P, Stricker BH CH. D rug-associated anaphylaxis: 20 years of reporting in the N etherland (1974-1994) and review of literature. Clin Exp Allergy 1996; 26: 1355-63.

3 A lkawajah A M, Eifawal M, M ahmoud SF. Fatal anaphylactic reaction to diclofenac. Forensic Sci Int 1993; 60: 107-10.

$4 \mathrm{Milman} \mathrm{U}, \mathrm{H}$ ermani $\mathrm{D}$. A naphylactic reaction to oral diclofenac sodium sustained release tablet. I sr J M ed Sci 1994; 30: 909-10.

Effects of pirenzepine, omeprazole, lansoprazole, and rabeprazole on human neutrophil functions

To the Editor:

Anesthesia and surgery inhibit several neutrophil functions $^{1}$ involved in antibacterial host defence mecha nisms. Pirenzepine (a muscarinic receptor antagonist) and omeprazole, lansoprazole, and rabeprazole (proton pump inhibitors) are administered peri-operatively for prophylaxis against aspiration pneumonitis or stress ulceration ${ }^{2-4}$ Critically ill patients, potentially immunocompromised, often receive these gastric protective agents for the same purpose. This is why, after institutional approvement and informed consent, we assessed chemotaxis, phagocytosis, and superoxide $\left(\mathrm{O}_{2}^{-}\right)$and hydrogen peroxide $\left(\mathrm{H}_{2} \mathrm{O}_{2}\right)$ production of neutrophils isolated from 12 healthy adult volunteers in the presence of pirenzepine, omeprazole, lansoprazole, or rabepra zole at clinically relevant concentrations, four times, and ten times these concentrations, according to methods described previously. ${ }^{5}$ We also measured intracellular calcium ion $\left(\left[\mathrm{Ca}^{++}\right]\right.$i) concentrations and $\mathrm{O}_{2}-$ and $\mathrm{H}_{2} \mathrm{O}_{2}$ production by the xanthine- xanthine oxidase system. Although pirenzepine, omeprazole, and lansoprazole had no effect on neutrophil chemotaxis, phagocytosis, $\mathrm{O}_{2}-$ and $\mathrm{H}_{2} \mathrm{O}_{2}$ production, and the stimulant-induced elevation of $\left[\mathrm{Ca}^{++}\right] \mathrm{i}$, rabeprazole inhibited these functions/ responses in a dose-dependent manner (Figure). Rabeprazole impaired chemotaxis at clinically relevant concentrations. All drugs failed to scavenge $\mathrm{O}_{2}$ - and $\mathrm{H}_{2} \mathrm{O}_{2}$ generated by an acellular system. Inhibition of calcium mobilization may have contributed, in part, to 